\title{
Synthesis and anti-tubercular activity of 3-substituted benzothiophene-1,1-dioxides
}

We demonstrated that the 3-substituted benzothiophene-1,1-dioxide class of compounds are effective inhibitors of Mycobacterium tuberculosis growth under aerobic conditions. We examined substitution at the C-3 position of the benzothiophene-1,1dioxide series systematically to delineate structure-activity relationships influencing potency and cytotoxicity. Compounds were tested for inhibitory activity against virulent M. tuberculosis and eukaryotic cells. The tetrazole substituent was most potent, with a minimum inhibitory concentration (MIC) of $2.6 \mu \mathrm{M}$. However, cytotoxicity was noted with even more potency (Vero cell TC50 $=0.1 \mu \mathrm{M})$. Oxadiazoles had good anti-tubercular activity (MICs of 3-8 $\mu \mathrm{M}$ ), but imidazoles, thiadiazoles and thiazoles had little activity. Cytotoxicity did not track with antitubercular activity, suggesting different targets or mode of action between bacterial and eukaryotic cells. However, we were unable to derive analogs without cytotoxicity; all compounds synthesized were cytotoxic (TC50 of $0.1-5 \mu \mathrm{M}$ ). We conclude that cytotoxicity is a liability in this series precluding it from further development. However, the series has potent anti-tubercular activity and future efforts towards identifying the mode of action could result in the identification of novel drug targets. 


\section{Synthesis and anti-tubercular activity of 3-substituted benzo[b]thiophene-1,1- 3 dioxides}

4 Authors

5 N. Susantha Chandrasekera, Mai A. Bailey, Megan Files, Torey Alling, Stephanie K. Florio, 6 Juliane Ollinger, Joshua O. Odingo, and Tanya Parish*

7 Affiliations

8 TB Discovery Research, Infectious Disease Research Institute, 1616 Eastlake Avenue E, Seattle, 9 WA 98102, USA.

$10 *$ Corresponding author. TB Discovery Research, Infectious Disease Research Institute, 1616

11 Eastlake Avenue E, Seattle, WA 98102, USA.

12 Tel.: 206858 6074; Fax: 2063813678

13 E-mail address: tanya.parish@idri.org.

14 Keywords: Benzo[b]thiophene-1,1-dioxide, Tuberculosis, Antimicrobial 


\section{Introduction}

16 Tuberculosis (TB), which is caused by Mycobacterium tuberculosis is the second leading cause

17 of death from an infectious disease and is a major global health problem. In 2010, according to

18 the World Health Organization (WHO) 8.8 million new cases and 1.4 million deaths from the

19 disease were reported [1]. In addition, one third of the world population has latent TB, $10 \%$ of

20 whom are expected to develop active TB at some point in their lives. Currently the recommended

21 first-line TB treatment regimens require a minimum of 6 months of multidrug therapy, resulting

22 in challenges with patient adherence. The result of inadequate therapy and poor compliance has

23 contributed to a rise in the emergence of multidrug resistant (MDR), resistant to isoniazid and

24 rifampicin, and extensively drug-resistant (XDR) strains, resistant to a fluoroquinolone and at

25 least one injectable drug, of M. tuberculosis [1]. Consequently, there is an urgent need for the

26 development of novel anti-TB drugs that are effective against both drug sensitive and resistant $M$.

27 tuberculosis [2].

28 The benzo[b]thiophene-1,1-dioxide (BTD) series was reported to have activity against $M$.

29 tuberculosis in a phenotypic assay []ㅡ. Fourteen compounds were tested from this series; five of

30 these, all of which had heteroarylthio groups, had some inhibitory activity against $M$.

31 tuberculosis. As a part of our ongoing TB drug discovery program, we were interested in

32 exploring the potential of the BTD series to be developed as a lead series for TB treatment. We

33 conducted an exploratory chemistry study and evaluated the series for their activity against $M$.

34 tuberculosis as well as cytotoxicity for eukaryotic cells.

\section{Materials and Methods}

\section{Determination of minimum inhibitory concentration (MIC)}


37 We used M. tuberculosis H37Rv (London Pride), a laboratory-passaged derivative of H37Rv

38 (ATCC 25618), which has been sequenced, as described in [్]. MICs were run as described [4];

39 briefly MICs were determined against M. tuberculosis grown in Middlebrook 7H9 medium

40 containing 10\% OADC (oleic acid, albumin, dextrose, catalase) supplement (Becton Dickinson)

41 and $0.05 \%$ w/v Tween 80 (7H9-Tw-OADC) under aerobic conditions. Compounds were prepared

42 as 10-point two-fold serial dilutions in DMSO with a starting concentration of $20 \mu \mathrm{M}$ (lowest

43 compound concentration $40 \mathrm{nM}$ ). The final concentration of DMSO in the assay was $2 \%$.

44 Bacterial growth was measured by $\mathrm{OD}_{590}$ after 5 days of incubation at $37^{\circ} \mathrm{C}$ and $\%$ growth

45 measured. Growth inhibition curves were plotted and fitted using the Gompertz model. The MIC

46 was defined as the minimum concentration required for $>99 \%$ growth inhibition.

\section{Vero cytotoxicity assay}

48 CellTiter-Glo ${ }^{\circledR}$ Luminescent Cell Viability Assay (Promega) was used to measure ATP as a

49 indicator of cell viability. The Vero cell line (ATCC CCL81) was grown in Dulbecco's Modified

50 Eagle Medium (DMEM), High Glucose, GlutaMAX ${ }^{\mathrm{TM}}$ (Invitrogen), 10\% FBS (Fetal Bovine

51 Serum), and $1 \mathrm{x}$ of Penicillin-Streptomycin Solution (100 units $/ \mathrm{mL}$ of penicillin, $100 \mu \mathrm{g} / \mathrm{mL}$ of

52 streptomycin). Compounds were solubilized in DMSO (dimethyl sulfoxide) and assayed using a

53 10-point three-fold serial dilution starting at the highest concentration of $50 \mu \mathrm{M}$. CellTiter-Glo ${ }^{\circledR}$

54 Reagent (Promega) was added to 96 -well plates after 2 days of incubation at $37^{\circ} \mathrm{C}, 5 \% \mathrm{CO}_{2}$.

55 Relative luminescent units (RLU) were measured using Perkin Elmer Wallac 1420 Victor2 plate

56 reader. Inhibition curves were fitted using the Levenberg-Marquardt algorithm. Toxic

57 concentration $\left(\mathrm{TC}_{50}\right)$ was defined as the concentration of compound that gave $50 \%$ inhibition of

58 growth. Selectivity index was calculated as $\mathrm{MIC} \mathrm{TC}_{50}$. For published data [3], SI was calculated 59 as $\mathrm{IC}_{90} / \mathrm{TC}_{50}$. 
60 Analysis of compounds

$61{ }^{1} \mathrm{H}$ and NMR spectral data were recorded in $\mathrm{CDCl}_{3}$ or Acetone-d6 on a $300 \mathrm{MHz}$ Bruker NMR

62 spectrometer. Column chromatography was conducted on a Revelaris flash chromatography

63 system. Reactions were monitored using thin-layer chromatography (TLC) on silica gel plates.

64 HPLC analysis was conducted on an Agilent 1100 series LC system (Agilent ChemStation

65 Rev.A.10.02; Phenomenex-Luna-C18, $4.8 \mathrm{~mm} \times 150 \mathrm{~mm}, 5 \mu \mathrm{m}, 1.0 \mathrm{~mL} / \mathrm{min}$, UV 254nm, room

66 temperature) with $\mathrm{MeCN} / \mathrm{H}_{2} \mathrm{O}(0.05 \%$ TFA or $\mathrm{HCOOH}$ buffer $)$ gradient elution. HPLC-MS was

67 performed on a Gilson 321 HPLC with detection performed by a Gilson 170 DAD and a Finnigan

68 AQA mass spectrometer operating in electrospray ionisation mode using a Phenomenex Gemini

69 C18 150x4.6mm column. Compounds 3a, b, c, s, t and u were purchased from ChemBridge

70 Corporation.

71 Synthesis of 3-bromobenzo[b]thiophene 1,1-dioxide (2)

72 To a solution of $11.62 \mathrm{~g}(7.6 \mathrm{mmol})$ in $25.0 \mathrm{~mL}$ in acetic acid was added $30 \%$ aqueous hydrogen

73 peroxide and the mixture was heated for $1 \mathrm{~h}$ at $100^{\circ} \mathrm{C}$. The mixture was poured into ice cold water

74 and let it stand overnight. The resulting solid was filtered and dried to yield $2(1.65 \mathrm{~g}, 89 \%)$. ${ }^{1} \mathrm{H}$

75 NMR (300 MHz, $\left.\mathrm{CDCl}_{3}\right): \delta 6.98(\mathrm{~s}, 1 \mathrm{H}), 7.58$ - $7.72(\mathrm{~m}, 4 \mathrm{H})$. LCMS - ESI $(\mathrm{M}+\mathrm{H})^{+}: 214.1$.

\section{General procedure for the synthesis of 3-substituted benzo[b]thiophene-1,1-dioxides}

77 To a solution of $200 \mathrm{mg}(0.82 \mathrm{mmol})$ of 2 in $5 \mathrm{~mL}$ of dimethyl formamide was added $2.0 \mathrm{mmol}$

78 of the thiol reagent followed by $0.5 \mathrm{~mL}$ of triethylamine. The reaction was stirred overnight and

79 washed with $20 \mathrm{~mL}$ of deionized water and extracted with $50 \mathrm{~mL}$ of ethyl acetate. The organic

80 layer was dried with anhydrous sodium sulfate, filtered and concentrated in vacuo. The resulting

81 residue was purified by reveleris flash chromatography system to yield the aryl/heteroaryl thio

82 benzo[b]thiophene 1,1-dioxides. 
83 3-((5-(4-methoxyphenyl)-1,3,4-oxadiazol-2-yl)thio)benzo[b]thiophene 1,1-dioxide (3d)

84 Yield 3d: (95 mg, 31\%). ${ }^{1} \mathrm{H}$ NMR (300 MHz, $\left.\mathrm{CDCl}_{3}\right)$ : 3.9 (3H, $\mathrm{OCH}_{3} . \quad$ s); $7.0-8.0(\mathrm{~m}, 9 \mathrm{H})$.

85 LCMS - ESI $(\mathrm{M}+\mathrm{H})^{+}: 373.0$.

86 3-((5-(4-chlorophenyl)-1,3,4-oxadiazol-2-yl)thio)benzo[b]thiophene 1,1-dioxide (3e)

87 Yield 3e: (122 mg, 39\%). ${ }^{1} \mathrm{H}$ NMR (300 MHz, Methanol-d 4$): 7.5-8.1$ (m, 8H). LCMS - ESI $88(\mathrm{M}+\mathrm{H})^{+}: 377.0$.

89 3-(thiazol-2-ylthio)benzo[b]thiophene 1,1-dioxide (3f)

90 Yield 3f: (87 mg, 31\%). ${ }^{1} \mathrm{H}$ NMR (300 MHz, $\left.\mathrm{CDCl}_{3}\right): 6.6(1 \mathrm{H}, \mathrm{s}) ; 7.6-8.1(\mathrm{~m}, 6 \mathrm{H})$. LCMS - ESI

$91(\mathrm{M}+\mathrm{H})^{+}: 282.0$.

92 3-((4-phenylthiazol-2-yl)thio)benzo[b]thiophene 1,1-dioxide (3g)

93 Yield 3g: (25 mg, 9\%). ${ }^{1} \mathrm{H}$ NMR (300 MHz, $\left.\mathrm{CDCl}_{3}\right)$ : $7.7-8.0(\mathrm{~m}, 10 \mathrm{H})$. LCMS - ESI (M+H)

94358.0.

95 3-(benzo[d]thiazol-2-ylthio)benzo[b]thiophene 1,1-dioxide (3h)

96 Yield 3h: (65 mg, 32\%). ${ }^{1} \mathrm{H}$ NMR (300 MHz, $\left.\mathrm{CDCl}_{3}\right): 7.3-8.1(\mathrm{~m}, 9 \mathrm{H})$. LCMS - ESI (M+H) ${ }^{+}$:

97332.0.

98 3-((5-chloro-3a,7a-dihydrobenzo[d]thiazol-2-yl)thio)benzo[b]thiophene 1,1-dioxide (3i)

99 Yield 3i: (25 mg, 30\%). ${ }^{1} \mathrm{H}$ NMR (300 MHz, $\left.\mathrm{CDCl}_{3}\right): 7.4(1 \mathrm{H}, \mathrm{s}) ; 7.5-8.1(\mathrm{~m}, 7 \mathrm{H})$. LCMS - ESI $100 \quad\left(2 \mathrm{M}+\mathrm{H}_{2} \mathrm{O}\right)^{+}: 754.9$. 
101 3-((6-ethoxybenzo[d]thiazol-2-yl)thio)benzo[b]thiophene 1,1-dioxide (3j)

102 Yield 3j: (105 mg, 28\%). ${ }^{1} \mathrm{H}$ NMR (300 MHz, $\left.\mathrm{CDCl}_{3}\right): 1.5(3 \mathrm{H}, \mathrm{d}) ; 4.1(2 \mathrm{H}, \mathrm{t}) ; 7.1-7.9$ (m, 8H).

103 LCMS - ESI $(\mathrm{M}+\mathrm{H})^{+}: 376.0$.

104 3-((5-methyl-1,3,4-thiadiazol-2-yl)thio)benzo[b]thiophene 1,1-dioxide (3k)

105 Yield 3k: (26 mg, 11\%). ${ }^{1} \mathrm{H}$ NMR (300 MHz, $\left.\mathrm{CDCl}_{3}\right)$ : $2.6\left(3 \mathrm{H}, \mathrm{CH}_{3}, \mathrm{~s}\right) ; 7.7-8.0(\mathrm{~m}, 9 \mathrm{H})$. LCMS $106-$ ESI $(\mathrm{M}+\mathrm{H})^{+}: 297.0$.

107 3-((5-amino-1,3,4-thiadiazol-2-yl)thio)benzo[b]thiophene 1,1-dioxide (3I)

108 Yield 31: (16 mg, 7\%). ${ }^{1} \mathrm{H}$ NMR (300 MHz, $\left.\mathrm{CDCl}_{3}\right)$ : $6.8(1 \mathrm{H}, \mathrm{s}) ; 7.3\left(2 \mathrm{H}, \mathrm{NH}_{2}, \mathrm{~s}\right) ; 7.6-7.8(\mathrm{~m}$, 109 4H). Yield 20: (5 mg, 2\%). ${ }^{1} \mathrm{H}$ NMR (300 MHz, $\left.\mathrm{CDCl}_{3}\right): 7.1(2 \mathrm{H}, \mathrm{s}) ; 7.6-7.8(\mathrm{~m}, 4 \mathrm{H}) ; 8.8(1 \mathrm{H}$, 110 SH, s). LCMS - ESI $(\mathrm{M}+\mathrm{H})^{+}:$298.0.

111 3-((5-mercapto-1,3,4-thiadiazol-2-yl)amino)benzo[b]thiophene 1,1-dioxide (3m)

112 Yield 3m: (5 mg, 2\%). ${ }^{1} \mathrm{H}$ NMR (300 MHz, $\left.\mathrm{CDCl}_{3}\right)$ : $7.1(2 \mathrm{H}, \mathrm{s}) ; 7.6-7.8(\mathrm{~m}, 4 \mathrm{H}) ; 8.8(1 \mathrm{H}, \mathrm{SH}$, 113 s). LCMS - ESI $(\mathrm{M}+\mathrm{H})^{+}: 298.0$.

114 3-((1H-benzo[d]imidazol-2-yl)thio)benzo[b]thiophene 1,1-dioxide (3n)

115 Yield 3n: (100 mg, 39\%). ${ }^{1} \mathrm{H}$ NMR (300 MHz, $\left.\mathrm{CDCl}_{3}\right): 6.7(1 \mathrm{H}, \mathrm{s}) ; 7.3-7.8$ (m, 9H). LCMS 116 ESI $(\mathrm{M}+\mathrm{H})^{+}: 315.0$.

117 3-((1-methyl-3a,7a-dihydro-1H-benzo[d]imidazol-2-yl)thio)benzo[b]thiophene 1,1-dioxide 118 (3o)

119 Yield 3o: (57 mg, 21\%). ${ }^{1} \mathrm{H}$ NMR (300 MHz, $\left.\mathrm{CDCl}_{3}\right): 3.9\left(3 \mathrm{H}, \mathrm{CH}_{3} . \mathrm{s}\right) ; 6.4(1 \mathrm{H}, \mathrm{s}) ; 7.3-7.8(\mathrm{~m}$, 120 8H). LCMS - ESI $(\mathrm{M}+\mathrm{H})^{+}:$329.0. 
121 3-((5-nitro-3a,7a-dihydro-1H-benzo[d]imidazol-2-yl)thio)benzo[b]thiophene

122 (3p)

123 Yield 3p: (142 mg, 48\%). ${ }^{1} \mathrm{H}$ NMR (300 MHz, $\left.\mathrm{CDCl}_{3}\right)$ : $7.5(1 \mathrm{H}, \mathrm{s}) ; 7.7-7.9(\mathrm{~m}, 4 \mathrm{H}) ; 8.2(2 \mathrm{H}$, 124 d); $8.5(1 \mathrm{H}, \mathrm{s})$. LCMS - ESI $(\mathrm{M}+\mathrm{H})^{+}: 360.0$.

125 3-((5-methoxy-3a,7a-dihydro-1H-benzo[d]imidazol-2-yl)thio)benzo[b]thiophene 1,1-dioxide 126 (3q)

127 Yield 3q: (97 mg, 34\%). ${ }^{1} \mathrm{H}$ NMR (300 MHz, Methanol-d 4 ): $3.8\left(3 \mathrm{H}, \mathrm{OCH}_{3} . \mathrm{s}\right) ; 6.6(1 \mathrm{H}, \mathrm{s}) ; 7.0-$ $1287.7(\mathrm{~m}, 7 \mathrm{H})$.

129 3-((1-methyl-1H-tetrazol-5-yl)thio)benzo[b]thiophene 1,1-dioxide (3r)

130 Yield 3r: (115 mg, 50\%). ${ }^{1} \mathrm{H}$ NMR (300 MHz, $\left.\mathrm{CDCl}_{3}\right): 4.3\left(3 \mathrm{H}, 3 \mathrm{CH}_{3}, \mathrm{~s}\right) ; 6.9(1 \mathrm{H}, \mathrm{s}) ; 7.5-8.1$ 131 (m, 7H). LCMS - ESI $(2 \mathrm{M}+\mathrm{H})^{+}: 561.0$.

132 3-(pyridin-2-ylthio)benzo[b]thiophene 1,1-dioxide (3v)

133 Yield 3v: (120 mg, 53\%). ${ }^{1} \mathrm{H}$ NMR (300 MHz, $\left.\mathrm{CDCl}_{3}\right)$ : $6.6-8.5(\mathrm{~m}, 9 \mathrm{H})$. LCMS - ESI (M+H) 134276.0.

135 3-(pyridin-4-ylthio)benzo[b]thiophene 1,1-dioxide (3w)

136 Yield 3w: (57 mg, 25\%). ${ }^{1} \mathrm{H}$ NMR (300 MHz, $\left.\mathrm{CDCl}_{3}\right)$ : $6.6-8.5(\mathrm{~m}, 9 \mathrm{H}) . \mathrm{LCMS}-\mathrm{ESI}(\mathrm{M}+\mathrm{H})^{+}$:

137276.0.

138 3-(isoquinolin-3-ylthio)benzo[b]thiophene 1,1-dioxide (3x)

139 Yield 3x: (95 mg, 36\%). ${ }^{1} \mathrm{H}$ NMR (300 MHz, $\left.\mathrm{CDCl}_{3}\right): 7.3-8.1(\mathrm{~m}, 6 \mathrm{H})$. 
140 3-(naphthalen-2-ylthio)benzo[b]thiophene 1,1-dioxide (3y)

141 Yield 3y: (110 mg, 42\%). ${ }^{1} \mathrm{H}$ NMR (300 MHz, $\left.\mathrm{CDCl}_{3}\right)$ : $5.8(1 \mathrm{H}, \mathrm{s}) ; 7.6-8.1(\mathrm{~m}, 11 \mathrm{H})$. LCMS 142 ESI $(\mathrm{M}+2 \mathrm{Na})^{+}: 671.0$.

\section{Results and Discussion}

144 BTD analogs were synthesized as outlined in Scheme 1. The oxidation of commercially available

145 3-bromothianaphthalene (1) with hydrogen peroxide afforded 3-bromobenzothiophene-1,1-

146 dioxide (2). This in turn was reacted with the corresponding thiols to afford the 3 -substituted

147 BTDs. To investigate the biological activity, we conducted a systematic exploration of the

148 aryl/heteroaryl substituents linked via a thioether to the C-3 position of the benzo[b]thiophene-

149 1,1-dioxide compound.

150 We probed the consequences of having oxazoles and oxadiazoles as substituents at the C-3

151 position. Compounds were tested for efficacy against a virulent strain of M. tuberculosis in liquid

152 culture under aerobic growth conditions [4]. All compounds had good activity and the minimum

153 inhibitory concentration (MIC) was very similar (3-8 $\mu \mathrm{M}$ ) (Table 1). The change in electronics

154 of the phenyl substituents had no effect on potency of the oxadiazole compounds. The addition of

155 the electron donating groups, methyl (3b), methoxy (3d) or an electron withdrawing Cl-group

156 (3e) to the para position of (3a) resulted in similar MIC values (Table 1). MICs were similar for

157 benzaoxazole $\mathbf{3 c}$ and the phenyl linked oxadiazoles (3a, $\mathbf{b}, \mathbf{d}$, and $\mathbf{e})$. This confirmed that the

158 series has good anti-tubercular activity. We tested compound activity against eukaryotic cells

159 using the Vero cell line (derived from African green monkey kidney cells). All of the compounds

160 had significant cytotoxicity, with $\mathrm{TC}_{50}$ values $<0.3 \mu \mathrm{M}$, suggesting that these compounds are

161 even more effective against eukaryotic cells (Table 1). Of the compounds we tested, two had 
162 previously been identified as having anti-tubercular activity (3a and $\mathbf{3 i})^{3}$. In this study $\mathbf{3 a}$

163 appeared to have a selectivity index (SI) of $>33$. However, in our assay this compound had a SI

164 of 0.03 . The compound 3a was reported to have anti-tubercular activity with an $\mathrm{IC}_{90}$ of $1.3 \mu \mathrm{M}$

$165\left(0.45 \mu \mathrm{g} / \mathrm{mL}\right.$ ) and a $\mathrm{TC}_{50}$ of $43 \mu \mathrm{M}$ (calculated from the published data using the equation $\mathrm{TC}_{50}=$

$\left.166 \mathrm{SI} \times \mathrm{IC}_{90}\right)$. Ananthan et al., calculated $\mathrm{IC}_{90}$ in their assay, representing the concentration required

167 to inhibit growth by $90 \%$, but in our experience IC $9_{0}$ and MIC (which we used) are very similar.

168 In our case it had an MIC of $3.1 \mu \mathrm{M}$ and a cytotoxicity of $0.1 \mu \mathrm{M}$. Therefore, the difference in SI

169 is primarily due to the difference in cytotoxicity data.

170 Since we had seen good activity with the compounds, but significant cytotoxicity, we determined

171 whether we could separate the two activities to generate potent, non-toxic compounds. We

172 examined the influence of thiazoles and thiadiazoles on the biological activity and cytotoxicity of

173 these BTD compounds. Anti-tubercular activity was diminished by the replacement of an

174 oxazole with either a thiazole or a thiadiazole; these compounds showed MICs $\geq 20 \mu \mathrm{M}$ (Table

175 2). The only exception was compound 3k which showed good activity $(9 \mu \mathrm{M})$, where the

176 addition of an electron donating ethoxy group to the benzothiazole compound improved its

177 potency to $5 \mu \mathrm{M}(\mathbf{3 i})$. In contrast, addition of an electron-withdrawing group diminished activity

178 in compound $\mathbf{3 j}$ (MIC $>20 \mu \mathrm{M}$, Table 2 ). Cytotoxicity was also reduced by $10-100$-fold, and

179 although the selectivity index (SI) was also improved the compounds were still more active

180 against eukaryotic cells with SI of $<0.2$ (Table 2). The benzothiazole compound 3i has

181 previously been reported ${ }^{3}$, but in contrast to our results, it had a SI $>150$, whereas our data

182 indicate that the $\mathrm{SI}=0.5$. The compound $3 \mathbf{i}$ was reported to have a $\mathrm{TB} \mathrm{IC}_{90}$ of $<0.3 \mu \mathrm{M}(<0.1$

$183 \mu \mathrm{g} / \mathrm{mL}$ ) and a $\mathrm{TC}_{50}$ of $45 \mu \mathrm{M}$. In our assays it gave a MIC of $20 \mu \mathrm{M}$ and a cytotoxicity of $1 \mu \mathrm{M}$.

184 In this case the difference in SI is due to both the difference in activity and cytotoxicity data. 
185 We then investigated the effect of C-3 imidazoles to see if we could improve the SI. Similar to

186 the thiazoles and thiadiazoles, this resulted in diminished activity $(\mathrm{MIC}>20 \mu \mathrm{M})(\mathbf{3 n}-\mathbf{3 q})$

187 (Table 3). Cytotoxicity was similar to those seen with the thiazole and thiadiazole groups.

188 Methylation of the $\mathrm{N}-1$ of the imidazole (3o) had no effect on activity (3n, $\mathbf{3 p}$ and $\mathbf{3 q}$ ). The 189 tetrazole compound (3r) showed the best activity of all the compounds synthesized (MIC $=2.6$ $190 \mu \mathrm{M}$ ), but also had significant cytotoxicity (Table 3).

191 Finally, we explored the influence of having six membered heterocycles in the C-3 position. We

192 synthesized compounds with pyrimidyl (3t), pyridyl (3v, 3w), quinolinyl (3u), or isoquinolinyl

193 (3x) groups and a non-heterocyclic compound with a naphthyl group (3y). All these analogs were

194 inactive suggesting that the BTD series requires a five membered heterocyclic substituent at the 195 C-3 position linked via a thioether for its activity against M. tuberculosis (Table 4).

\section{Conclusions}

197 We conducted a systematic exploration of the aryl/heteroaryl thioether substituents at the C-3

198 position of the benzo[b]thiophene-1,1-dioxide compound series for its inhibitory activity against

199 M. tuberculosis. The series exhibited encouraging activity with some MIC values $<10 \mu \mathrm{M}$. The

200 tetrazole, oxazole and the oxadiazoles were the most potent compounds tested, whereas

201 compounds bearing six-membered aromatic substituents at the C-3 position were inactive.

202 However, the BTD series was also active against eukaryotic cells showing significant toxicity

203 against the Vero cell line; in fact cytotoxicity was more pronounced than the anti-mycobacterial

204 activity. Our data are in contrast to that previously reported in which cytotoxicity was not

205 observed in selected members of the series []ㅡ. Differences in cytotoxicity could be due to the 206 exact assay method and the cell line used; in this case we used the same Vero cell line.

207 However, the assays conditions were different; we used passaged cells which were actively 
208 replicating as opposed to cells recovered directly from frozen. Since the majority of

209 cytotoxicity is manifested during cell division, this may account for our increased sensitivity. In

210 any case, we found that the series as a whole was cytotoxic. We were unable to reduce

211 cytotoxicity in this series, even after significant modifications of the third position substituent. On

212 this basis we concluded that the series lacks further potential for drug development. However, the

213 target of the series may still be of interest, since one might find alternative scaffolds with

214 specificity. Thus, in future, we are interested in finding the target of these compounds.

\section{Acknowledgements}

216 We thank Alfredo Blakeley, David Roberts and Yulia Ovechkina for technical assistance.

\section{References}

218 1. WHO 2011 Report: global tuberculosis control. Geneva: World Health Organization.

219 2. Ginsberg A. 2010. Drugs in development for tuberculosis. Drugs 70:2201-2204.

220 3. Ananthan S, Faaleolea ER, Goldman RC, Hobrath JV, Kwong CD, Laughon BE, Maddry AJ,

221 Mehta A, Rasmussen L, Reynolds RC, Secrist III JA, Shindo N, Showe DN, Sosa MI, Suling WJ,

222 White EL. 2009. High-throughput screening for inhibitors of Mycobacterium tuberculosis

223 H37Rv. Tuberculosis 89: 334-353.

224 4. Ollinger J, Bailey M, Moraski GC, Casey A, Florio S, Alling T, Miller MJ, Parish T. 2013. A

225 dual read-out assay to evaluate the potency of compounds active against Mycobacterium

226 tuberculosis. PLOS One 8: e60531.

227 5. Ioerger TR, Feng Y, Ganesula K, Chen X, Dobos KM, Fortune S, Jacobs WR, Mizrahi V,

228 Parish T, Rubin E, Sassetti C, Sacchettini JC. 2010. Variation among genome sequences of 
229 H37Rv strains of Mycobacterium tuberculosis from multiple laboratories. J. Bacteriology 192:

$230 \quad 3645-3653$. 


\section{Table $\mathbf{1}_{\text {(on next page) }}$}

Activity of oxazole and oxadiazole analogs of the BTD series against M. tuberculosis and Vero cell line.

$\mathrm{a}=\mathrm{MIC}$ is the minimum concentration required to inhibit growth completely of $M$. tuberculosis in liquid culture ${ }^{4}$. MICs of active compounds are the average of two independent experiments \pm standard deviation. $\mathrm{b}=\mathrm{TC}_{50}$ is concentration required to inhibit growth of Vero cells by $50 \%$. $\mathrm{TC}_{50}$ is the average of two runs \pm standard deviation. $\mathrm{C}=\mathrm{SI}$ is the selectivity index. Selectivity index is calculated as $\mathrm{MIC} / \mathrm{TC}_{50}$. For comparison, MIC of rifampicin is $0.003 \mu \mathrm{M}$ and isoniazid is $0.2 \mu \mathrm{M}[4]$. 


\begin{tabular}{|c|c|c|c|c|}
\hline Compound & R-group & $\operatorname{MIC}(\mu \mathrm{M})^{\mathrm{a}}$ & $\mathrm{TC}_{50}(\mu \mathrm{M})^{\mathrm{b}}$ & $\mathrm{SI}{ }^{\mathrm{C}}$ \\
\hline $3 a$ & & $3.1 \pm 0.07$ & $0.1 \pm 0$ & 0.03 \\
\hline $3 b$ & & $8.2 \pm 0.6$ & $0.2 \pm 0$ & 0.02 \\
\hline $3 c$ & & $5.7 \pm 2.9$ & $0.2 \pm 0.07$ & 0.04 \\
\hline $3 d$ & & $7.2 \pm 0.3$ & $0.3 \pm 0.3$ & 0.04 \\
\hline $3 e$ & & $3.9 \pm 1.7$ & $0.3 \pm 0.2$ & 0.08 \\
\hline
\end{tabular}

Table 1. Activity of oxazole and oxadiazole analogs of the BTD series against $M$. tuberculosis and Vero cell line.

$\mathrm{a}=\mathrm{MIC}$ is the minimum concentration required to inhibit growth completely of M. tuberculosis in liquid culture ${ }^{4}$. MICs of active compounds are the average of two independent experiments \pm standard deviation.

$\mathrm{b}=\mathrm{TC}_{50}$ is concentration required to inhibit growth of Vero cells by $50 \%$. $\mathrm{TC}_{50}$ is the average of two runs \pm standard deviation.

$\mathrm{c}=\mathrm{SI}$ is the selectivity index. Selectivity index is calculated as $\mathrm{MIC} / \mathrm{TC}_{50}$.

For comparison, MIC of rifampicin is $0.003 \mu \mathrm{M}$ and isoniazid is $0.2 \mu \mathrm{M}$ [4]. 


\section{Table 2 (on next page)}

Activity of thiazole and thiadiazole analogs of the BTD series against $M$. tuberculosis and Vero cell line.

$\mathrm{a}=\mathrm{MIC}$ is the minimum concentration required to inhibit growth completely of $M$. tuberculosis in liquid culture ${ }^{4}$. MICs of active compounds are the average of two independent experiments \pm standard deviation. $\mathrm{b}=\mathrm{TC}_{50}$ is concentration required to inhibit growth of Vero cells by $50 \%$. $\mathrm{TC}_{50}$ is the average of two runs \pm standard deviation. $\mathrm{C}=\mathrm{SI}$ is the selectivity index. Selectivity index is calculated as MIC/ TC ${ }_{50}$. For comparison, MIC of rifampicin is $0.003 \mu \mathrm{M}$ and isoniazid is $0.2 \mu \mathrm{M}[4]$. 


\begin{tabular}{|c|c|c|c|c|}
\hline Compound & R-group & $\operatorname{MIC}(\mu \mathrm{M})^{a}$ & $\mathrm{TC}_{50}(\mu \mathrm{M})^{\mathrm{b}}$ & $\mathrm{SI}^{\circ}$ \\
\hline $3 \mathbf{g}$ & & 20 & 1 & 0.05 \\
\hline $3 \mathrm{~h}$ & & 20 & $3 \pm 1.2$ & 0.2 \\
\hline $3 i$ & & 20 & 1 & 0.05 \\
\hline $3 \mathbf{j}$ & & $>20$ & $1 \pm 0.4$ & NC \\
\hline $3 k$ & & $9.0 \pm 4.7$ & $1 \pm 0.1$ & 0.1 \\
\hline 31 & & $>20$ & $1 \pm 0.4$ & NC \\
\hline $3 m$ & & $>20$ & $3 \pm 1$ & NC \\
\hline $3 n$ & & 20 & $3 \pm 0.7$ & 0.2 \\
\hline
\end{tabular}

Table 2. Activity of thiazole and thiadiazole analogs of the BTD series against $M$. tuberculosis and Vero cell line.

$\mathrm{a}=\mathrm{MIC}$ is the minimum concentration required to inhibit growth completely of $M$. tuberculosis in liquid culture ${ }^{4}$. MICs of active compounds are the average of two independent experiments \pm standard deviation.

$\mathrm{b}=\mathrm{TC}_{50}$ is concentration required to inhibit growth of Vero cells by $50 \% . \mathrm{TC}_{50}$ is the average of two runs \pm standard deviation.

$\mathrm{c}=\mathrm{SI}$ is the selectivity index. Selectivity index is calculated as $\mathrm{MIC} / \mathrm{TC}_{50}$.

$\mathrm{NC}=$ not calculated. 


\section{Table 3 (on next page)}

Activity of imidazole and tetrazole analogs of the BTD series against $M$. tuberculosis and Vero cell line.

$\mathrm{a}=\mathrm{MIC}$ is the minimum concentration required to inhibit growth completely of $M$. tuberculosis in liquid culture ${ }^{4}$. MICs of active compounds are the average of two independent experiments \pm standard deviation. $\mathrm{b}=\mathrm{TC}_{50}$ is concentration required to inhibit growth of Vero cells by $50 \%$. $\mathrm{TC}_{50}$ is the average of two runs \pm standard deviation. $\mathrm{C}=\mathrm{SI}$ is the selectivity index. Selectivity index is calculated as $\mathrm{MIC} / \mathrm{TC}_{50} . \mathrm{NC}=$ not calculated. $\mathrm{ND}=$ not determined. 


\begin{tabular}{|c|c|c|c|c|}
\hline Compound & R-group & $\operatorname{MIC}(\mu \mathrm{M})^{a}$ & $\mathrm{TC}_{50}(\mu \mathrm{M})^{\mathrm{b}}$ & $\mathrm{SI}^{\circ}$ \\
\hline $3 n$ & & $>20$ & 1 & NC \\
\hline 30 & & $>20$ & 5 & NC \\
\hline & & $>20$ & ND & NC \\
\hline $3 q$ & & $>20$ & $0.3 \pm 0.07$ & NC \\
\hline $3 r$ & $\mathcal{M e ́}_{N}^{N-N}$ & 2.6 & $0.1 \pm 0$ & 0.004 \\
\hline
\end{tabular}

Table 3. Activity of imidazole and tetrazole analogs of the BTD series against $M$. tuberculosis and Vero cell line.

$\mathrm{a}=\mathrm{MIC}$ is the minimum concentration required to inhibit growth completely of $M$. tuberculosis in liquid culture ${ }^{4}$. MICs of active compounds are the average of two independent experiments \pm standard deviation.

$\mathrm{b}=\mathrm{TC}_{50}$ is concentration required to inhibit growth of Vero cells by $50 \%$. $\mathrm{TC}_{50}$ is the average of two runs \pm standard deviation.

$\mathrm{c}=\mathrm{SI}$ is the selectivity index. Selectivity index is calculated as $\mathrm{MIC} / \mathrm{TC}_{50}$.

$\mathrm{NC}=$ not calculated.

$\mathrm{ND}=$ not determined 


\section{Table 4 (on next page)}

Activity of six membered heterocyclic analogs of the BTD series against $M$. tuberculosis and Vero cell line.

$\mathrm{a}=\mathrm{MIC}$ is the minimum concentration required to inhibit growth completely of $M$. tuberculosis in liquid culture ${ }^{4}$. MICs of active compounds are the average of two independent experiments \pm standard deviation. $\mathrm{b}=\mathrm{TC}_{50}$ is concentration required to inhibit growth of Vero cells by $50 \%$. $\mathrm{TC}_{50}$ is the average of two runs \pm standard deviation. $\mathrm{C}=\mathrm{SI}$ is the selectivity index. Selectivity index is calculated as $\mathrm{MIC} / \mathrm{TC}_{50} . \mathrm{NC}=$ not calculated. $\mathrm{ND}=$ not determined. 


\begin{tabular}{|c|c|c|c|c|}
\hline Compound & R-group & $\operatorname{MIC}(\mu \mathrm{M})^{a}$ & $\mathrm{TC}_{50}(\mu \mathrm{M})^{\mathrm{b}}$ & $S I^{\circ}$ \\
\hline $3 \mathrm{~s}$ & & $>20$ & $10 \pm 1$ & NC \\
\hline $3 t$ & & $>20$ & ND & NC \\
\hline $3 u$ & & $>20$ & ND & NC \\
\hline $3 v$ & & $>20$ & ND & NC \\
\hline $3 w$ & & $>20$ & ND & NC \\
\hline $3 x$ & & $>20$ & ND & NC \\
\hline $3 y$ & & $>20$ & ND & NC \\
\hline
\end{tabular}

Table 4. Activity of six membered heterocyclic analogs of the BTD series against $M$. tuberculosis and Vero cell line.

$\mathrm{a}=\mathrm{MIC}$ is the minimum concentration required to inhibit growth completely of $M$. tuberculosis in liquid culture ${ }^{4}$. MICs of active compounds are the average of two independent experiments \pm standard deviation.

$\mathrm{b}=\mathrm{TC}_{50}$ is concentration required to inhibit growth of Vero cells by $50 \% . \mathrm{TC}_{50}$ is the average of two runs \pm standard deviation.

$\mathrm{c}=\mathrm{SI}$ is the selectivity index. Selectivity index is calculated as $\mathrm{MIC} / \mathrm{TC}_{50}$.

$\mathrm{NC}=$ not calculated.

$\mathrm{ND}=$ not determined 


\section{Table 5(on next page)}

Synthesis of 3-substituted benzo[b]thiophene-1,1-dioxides. 


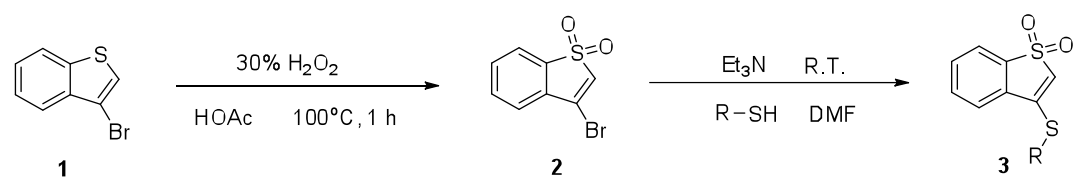

Scheme 1. Synthesis of 3-substituted benzo[b]thiophene-1,1-dioxides. 